\title{
TRIB3 is implicated in glucotoxicity- and oestrogen receptor-stress-induced $\beta$-cell apoptosis
}

\author{
Bo Qian ${ }^{1,2}$, Haiyan Wang ${ }^{3}$, Xiuli Men ${ }^{2}$, Wenjian Zhang ${ }^{2}$, Hanqing $\mathrm{Cai}^{2}$, Shiqing $\mathrm{Xu}^{2}$, \\ Yaping $\mathrm{Xu}^{2}$, Liya $\mathbf{Y e}^{2}$, Claes B Wollheim ${ }^{3}$ and Jinning Lou $^{2}$ \\ ${ }^{1}$ Graduate School of Peking Union Medical College, Beijing 100730, People's Republic of China \\ ${ }^{2}$ Institute of Clinical Medical Sciences, China-Japan Friendship Hospital, Beijing 100029, People's Republic of China \\ ${ }^{3}$ Department of Cell Physiology and Metabolism, University Medical Center, 1 rue Michel-Servet, CH-1211 Geneva 4, Switzerland \\ (Correspondence should be addressed to J Lou; Email: lou.j@mail.com)
}

\begin{abstract}
We found that TRIB3, an endogenous inhibitor of Akt (PKB), is expressed in pancreatic $\beta$-cells. The TRIB3 expression is significantly increased in islets isolated from hyperglycemic Goto-Kakizaki rats compared with normal glycemic controls. In vitro high glucose treatment also resulted in increased TRIB3 expression in rat INS1 cells. To investigate the role of TRIB3 in the regulation of $\beta$-cell function, we established an INS1 stable cell line allowing inducible expression of TRIB3. We demonstrated that overexpression of TRIB3 mimicked the glucotoxic effects on insulin secretion and cell growth in INS1 cells. Moreover, induction of TRIB3 also synergistically enhanced highglucose-elicited apoptosis in INS1 cells, whereas siRNA knock-down of TRIB3 showed the opposite effects. We also
\end{abstract}

confirmed that the $\Delta \Psi \mathrm{m}$ of mitochondria was decreased, caspase-3 activity was up-regulated and reactive oxygen species content was increased in TRIB3 overexpressing $\beta$ cells in high glucose condition. Most interestingly, the oestrogen receptor (ER) stress inducer, thapsigargin, mimicked the high glucose effects on up-regulation of TRIB3 and generation of apoptosis in cultured INS1 cells. These effects were specifically prevented by siRNA knock down of TRIB3. We therefore conclude that TRIB3 is implicated in glucotoxicity- and ER stress-induced $\beta$-cell failure. TRIB3 could be a potential pharmacological target for prevention and treatment of type 2 diabetes.

Journal of Endocrinology (2008) 199, 407-416

\section{Introduction}

Progressive $\beta$-cell failure is the precipitating factor for the transition from the insulin-resistant state to overt type 2 diabetes (Muoio \& Newgard 2008). Hyperglycemia and oestrogen receptor (ER) stress have been suggested as causing factors of $\beta$-cell dysfunction (Grill \& Björklund 2001, Harding et al. 2001, Laybutt et al. 2007, Marchetti et al. 2007, Eizirik et al. 2008). However, the underlying mechanisms remain to be elucidated.

ER stress has been implicated in chronic glucotoxicityinduced $\beta$-cell apoptosis (Wang et al. 2005, Laybutt et al. 2007, Marchetti et al. 2007, Eizirik et al. 2008). It has also been demonstrated that up-regulation of tribbles homolog 3 (Drosophila; TRIB3) is one of the major mechanisms involved in ER stress-induced cell death via the ATF4-CHOP pathway in non- $\beta$-cells (Ohoka et al. 2005, Carracedo et al. 2006). It is, therefore, of interest to study the involvement of TRIB3 in glucotoxicity- and ER stress-induced $\beta$-cell dysfunction and apoptosis.

TRIB3, a mammalian homolog of Drosophila tribbles, is also known as neuronal cell death-inducible putative protein kinase, because it is discovered to be expressed in neuronal

cells undergoing apoptosis resulting from either, neurotrophic factor deprivation or disrupted calcium homeostasis (Mayumi-Matsuda et al. 1999). It has a kinase-like domain but is lacking kinase activity (Mayumi-Matsuda et al. 1999, Boudeau et al. 2006). TRIB3 has recently attracted interest in diabetes research as it has emerged as an endogenous inhibitor of Akt (PKB), which plays a key role in insulin signaling (Du et al. 2003). In addition, the mRNA levels of TRIB3 are elevated in the liver of $d b / d b$ mice (Matsushima et al. 2006). Moreover, adenovirus-mediated overexpression of TRIB3 in mouse liver results in hyperglycemia by inhibition of insulin action on glycogen synthesis and gluconeogenesis (Du et al. 2003, Koo et al. 2004). By contrast, knockdown of TRIB3 in mouse liver or muscle improves insulin action and glucose tolerance (Koo et al. 2004, Koh et al. 2006). Therefore, TRIB3 may contribute to the development of insulin resistance.

However, nothing is known regarding the role of TRIB3 in the regulation of $\beta$-cell function. The present work is designed to study the possible involvement of TRIB3 in glucotoxicity and ER stress-evoked $\beta$-cell dysfunction and apoptosis. 


\section{Materials and Methods}

\section{Islet isolation from Goto-Kakizaki (GK) rat}

All animal experimental procedures were performed in accordance with China-Japan Friendship Hospital's Animal Studies Committee. Islets were isolated from five hyperglycemic GK rats (mean non-fasting blood glucose $19.54 \mathrm{mmol} / \mathrm{l}$ ) and five normal glycemic GK rats (mean non-fasting blood glucose $4.16 \mathrm{mmol} / \mathrm{l}$; Shanghai Slac Laboratory animal Co. Ltd, Shanghai, China) using the intraductal collagenase digestion technique described previously (Shapiro et al. 1996). Briefly, $10 \mathrm{ml}$ Hank's balanced salt solution with $2 \mathrm{mg} / \mathrm{ml}$ collagenase type IV (Sigma) were injected into the pancreatic duct. After pancreatectomy, the pancreata were digested in a $37^{\circ} \mathrm{C}$ water bath for $19 \mathrm{~min}$. the isolated islets were further purified by Ficoll (Sigma) gradient centrifugation. The purified islets were washed thrice and subjected to total RNA extraction.

\section{Total RNA extraction and real-time PCR}

RNeasy mini kit (Qiagen) was used, following manufacturer's protocol, for total RNA extraction from either INS1-derived cells or isolated islets. One microgram total RNA was used for reverse transcription using omniscript reverse transcriptase (Qiagen). Real-time PCR was performed on an Applied Biosystems ABI 7000, using SYBR Green PCR Master Mix (Qiagen) and 1/40 of RT reaction. At the end of each reaction, a melting curve analysis was performed to confirm the absence of primer dimmers. Expression levels of TRIB3 gene were normalized to the expression level of $\beta$-actin. The data was analyzed using the $2^{-\Delta \Delta C_{\mathrm{t}}}$ method. Primer sequences are as follows:

rat TRIB3: forward 5'-TGT CTT CAG CAA CTG TGA GAG GAC GAA G-3', reverse 5'-GTA GGA TGG CCG GGA GCT GAG TAT C- $3^{\prime}$;

rat $\beta$-actin: forward $5^{\prime}$-GAC ATC CGT AAA GAC CTC TAT GCC-3', reverse 5'-ATA GAG CCA CCA ATC CAC ACA GAG-3'.

\section{Establishment of INS1 stable cell lines allowing inducible expression of TRIB3}

The plasmids were constructed by subcloning the cDNAs encoding TRIB3. The stable INS-râ cells (also refer to as r9), which carries the reverse tetracycline/doxycycline-dependent transactivator (Gossen et al. 1995), were used for the secondary stable transfection following the procedures described previously (Wang \& Iynedjian 1997).

\section{Immunofluorescence staining}

The cells were cultured on cover slips in a 24-well plate in a $37^{\circ} \mathrm{C}$ and $5 \% \mathrm{CO}_{2}$ incubator for 2 days before treatment with or without $500 \mathrm{ng} / \mathrm{ml}$ doxycycline for induction of TRIB3 expression. After $48 \mathrm{~h}$ incubation, the cells were fixed in $4 \%$ paraformaldehyde, permeabilized with $0.1 \%$ Triton X-100 in PBS containing $0.5 \%$ BSA (PBS-BSA) for $30 \mathrm{~min}$. The cells were then incubated with rabbit anti-TRIB3 polyclonal antibody (Calbiochem, San Diego, CA, USA) at 1:200 dilutions for $45 \mathrm{~min}$, followed by labeling with FITC-conjugated rat antirabbit IgG antibody (Sigma) at 1:100 dilutions for $30 \mathrm{~min}$. The cells were viewed under a fluorescent microscope.

\section{Western blotting}

For western blotting, cells were cultured in flasks for 24-96 h before being treated with indicated concentrations of doxycycline at the specified time under either standard $(11.2 \mathrm{mmol} / \mathrm{l})$ or high $(30 \mathrm{mmol} / \mathrm{l})$ glucose conditions. All these cells were collected and lysed by sonication. The protein was extracted in buffer containing $20 \mathrm{mM}$ Tris-HCl, pH 7.4, $2 \mathrm{mM}$ EDTA, $150 \mu \mathrm{M} \mathrm{NaCl}, 10 \mathrm{mM} \mathrm{NaP}, 1 \% \mathrm{NP}-40$, and $1 \mathrm{mM}$ phenylmethylsulfonyl fluoride. Total cellular proteins were fractionated by $10 \%$ SDS-PAGE. Immunoblotting was performed using either aforementioned anti-TRIB3 antibody (1:500) or mouse anti- $\boldsymbol{\alpha}$-tubulin (Santa Cruz, CA, USA, 1:500) as described previously using enhanced chemiluminescence (Millipore, Billerica, MA, USA) for detection.

\section{Measurements of insulin secretion and cellular insulin content}

Cells were cultured in 24 -well plates in $11.2 \mathrm{mmol} / 1$ glucose medium with or without $500 \mathrm{ng} / \mathrm{ml}$ doxycycline for $48 \mathrm{~h}$. The cells were then incubated with Krebs-Ringer bicarbonateHEPES buffer containing $2.5 \mathrm{mmol} / 1$ glucose (Basal) or $20 \mathrm{mmol} / \mathrm{l}$ glucose (Glucose). The cell supernatant was collected after $30 \mathrm{~min}$ of stimulation and insulin content was determined after extraction with acid ethanol following the procedures described by Wang et al. (2002). Insulin concentration was determined by ELISA kits (Linco, St Charles, MO, USA).

\section{DNA fragmentation}

Cells were cultured in medium containing either $11.2 \mathrm{mmol} / \mathrm{l}$ glucose or $30 \mathrm{mmol} / 1$ glucose for $96 \mathrm{~h}$, in the presence or absence of $500 \mathrm{ng} / \mathrm{ml}$ doxycycline. The cells were washed twice with PBS, resuspended in the lysis buffer $(10 \mathrm{mM}$ Tris- $\mathrm{HCl}, \mathrm{pH}$ 8.0 and $10 \mathrm{mM}$ EDTA, $10 \mathrm{mM} \mathrm{NaCl}, 0.5 \%$ SDS, $100 \mu \mathrm{g} / \mathrm{ml}$ proteinase $\mathrm{K}$ ) and stored at $50{ }^{\circ} \mathrm{C}$ for $2 \mathrm{~h}$. The crude DNA preparations were further extracted and precipitated. The DNA pellets were air-dried and resuspended in $100 \mu \mathrm{l}$ TE buffer (10 mM Tris-HCl, pH 8.0, 1 mM EDTA) containing $100 \mathrm{~g} / \mathrm{ml}$ RNase. The concentration of nucleic acid was determined by u.v. absorbance at $260 \mathrm{~nm}$. The same amount of nucleic acids from each sample was found by electrophoresis on a $1.5 \%$ agarose gel and visualized by u.v. fluorescence after staining with ethidium bromide. Gel was visualized and photographed on an image analyzer instrument (Alphalmager 2000, Alpha Innotech Corp., San Leandro, CA, USA). 
Terminal deoxymucleotidyl transferase-mediated dUTP nick-end labeling (TUNEL) staining

Cells were cultured in a 96-well plate for 2 days and then the cells were treated with or without $500 \mathrm{ng} / \mathrm{ml}$ doxycycline in medium containing indicated glucose for $96 \mathrm{~h}$. The cells were washed, fixed in 4\% paraformaldehyde and then permeabilized with $0 \cdot 1 \%$ Triton X-100 in PBS/BSA solution. The TUNEL assay was performed using in situ cell death detection kits according to the recommendations of the manufacturer (Roche).

\section{Assessment of phosphatidylserine exposure}

The exposure of phosphatidylserine has been shown to be a sensitive marker of apoptosis in cells. Cells were cultured in medium containing $11.2 \mathrm{mmol} / 1$ or $30 \mathrm{mmol} / 1$ glucose in the presence or absence of $500 \mathrm{ng} / \mathrm{ml}$ doxycycline for $96 \mathrm{~h}$. The cells were washed once in PBS and incubated with $10 \mu \mathrm{l}$ $(20 \mu \mathrm{g} / \mathrm{ml})$ Annexin V-FITC according to the manufacturer's instructions. The cells were incubated with $5 \mu \mathrm{l}(50 \mu \mathrm{g} / \mathrm{ml})$ propidium iodide for $2 \mathrm{~min}$ on ice and then analyzed by FAC Scan (Beckman Counter Epics XL, Fullerton, CA, USA). This assay discriminates between intact cells (FITC-/PI-), early apoptotic cells (FITC $+/ \mathrm{PI}-$ ), and late apoptotic or necrotic cells $($ FITC $+/ \mathrm{PI}+$ or $\mathrm{PI}+)$.

\section{Measurement of mitochondrial membrane potential $\left(\Delta \Psi_{m}\right)$}

To measure mitochondrial $\Delta \Psi \mathrm{m}$, cells were loaded with $10 \mathrm{nM}$ $\mathrm{DiOC}_{6}(3)$ at $37^{\circ} \mathrm{C}$ for $5 \mathrm{~min}$. The cells were washed once and resuspended in PBS for FACScan analysis. The cells were then treated with the mitochondrial membrane uncoupler carbonyl cyanide m-chlorophenyl hydrazone at $10 \mu \mathrm{M}$ for $20 \mathrm{~min}$ at $37^{\circ} \mathrm{C}$ as a positive control for dissipation of $\Delta \Psi \mathrm{m}$.

\section{Measurement of caspase-3 activity}

Cells were cultured in 6-well plates with medium containing 11.2 or $30 \mathrm{mmol} / 1$ glucose in the presence or absence of $500 \mathrm{ng} / \mathrm{ml}$ doxycycline for $96 \mathrm{~h}$. The cells were harvested and washed thrice by PBS. Caspase-3 activity was measured by caspase-3 Assay Kit (Molecular Probe, Invitrogen) following the manufacturer's protocol then detected by micro plate fluorescence reader (Molecular Devices Corp, Sunnyvale, CA, USA).

Reactive oxygen species (ROS) assay by flow cytometry and xanthine oxidase (XOD) measurement

ROS formation was analyzed by flow cytometry according to the method previously described (Shih et al. 2004). Cells were cultured in 6-well plates with medium containing 11.2 or $30 \mathrm{mmol} / 1$ glucose in the presence or absence of $500 \mathrm{ng} / \mathrm{ml}$ doxycycline for $96 \mathrm{~h}$. The cells were washed twice with PBS, stained with CM-H $\mathrm{H}_{2}$ DCFDA $(1 \mathrm{mM})$ in $\mathrm{PBS}(\mathrm{pH} \cdot 2)$ at $37^{\circ} \mathrm{C}$ for $5 \mathrm{~min}$ and then PI (to $10 \mathrm{mg} / \mathrm{ml}$ ) was added for $1 \mathrm{~min}$.
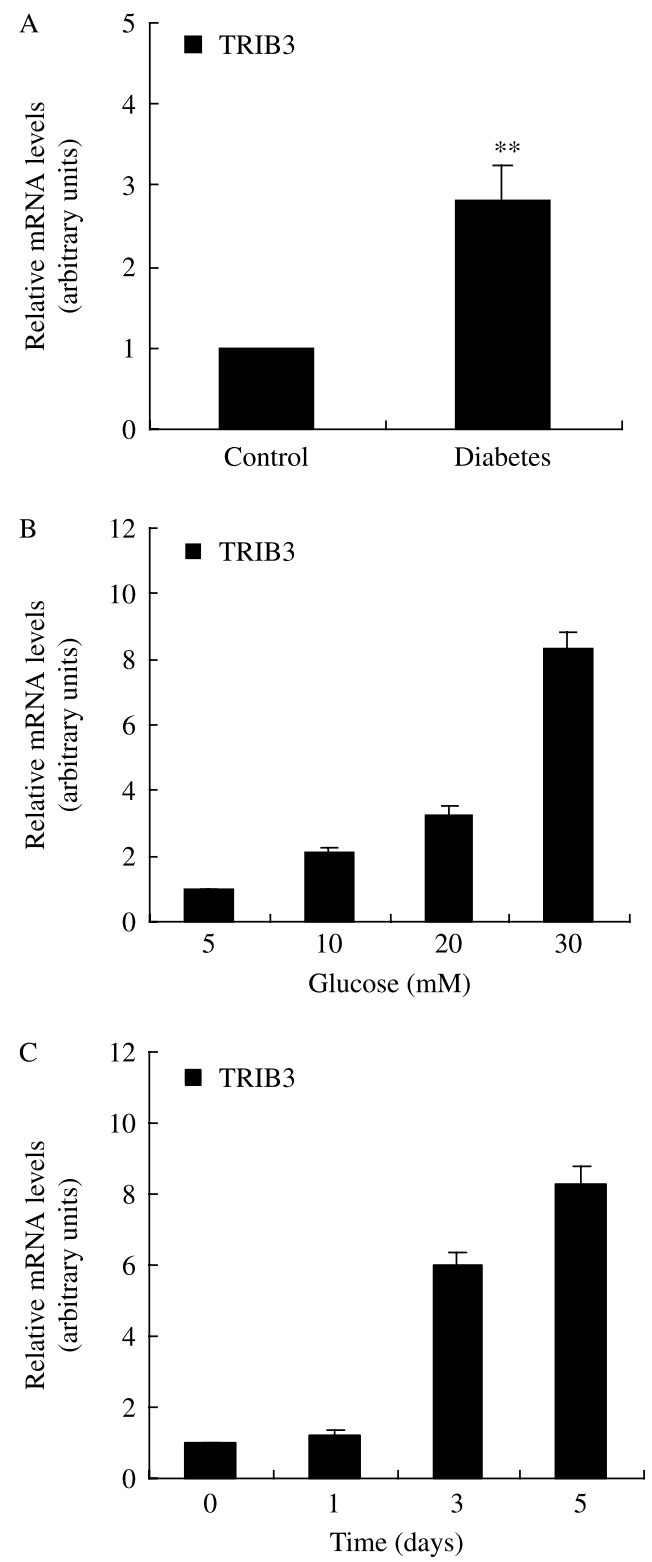

Figure 1 Real-time PCR analysis of effects of high glucose on TRIB3 expression in GK rat islets and INS1-derived cells. (A) TRIB3 expression was increased in diabetic GK rat islets: TRIB3 mRNA levels in islets isolated from hyperglycemic GK rats (mean nonfasting blood glucose $19 \cdot 54 \mathrm{mmol} / \mathrm{l}$ ) were $2 \cdot 8$-fold higher than those of control normal glycemic GK rats (mean non-fasting blood glucose $4 \cdot 16 \mathrm{mmol} / \mathrm{l})$. $\left({ }^{* *} P<0 \cdot 01\right)$ (B) Dose-response of glucose on TRIB3 transcript levels in INS-r $\beta$ cells. INS1-derived cells were cultured for 5 days in medium containing respectively $5,10,20$, and $30 \mathrm{mM}$ glucose. Data represent mean \pm s.D. of three independent experiments $(* * P<0 \cdot 01)$. (C) Time course of high glucose effects on TRIB3 expression. INS- $r \beta$ cells were cultured in $30 \mathrm{mM}$ glucose medium for $0,1,3$, and 5 days respectively. Data represent mean \pm s.D. of three independent experiments $(* * P<0 \cdot 01)$. 


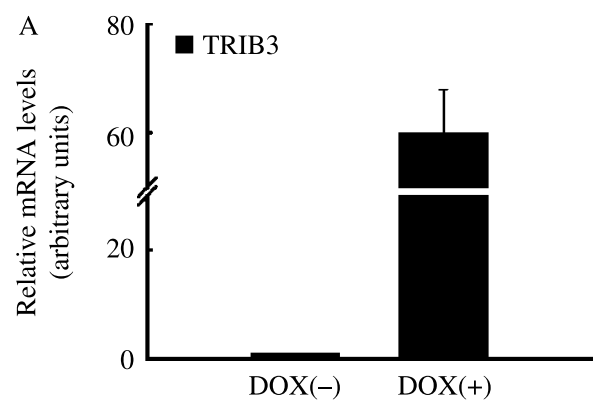

B
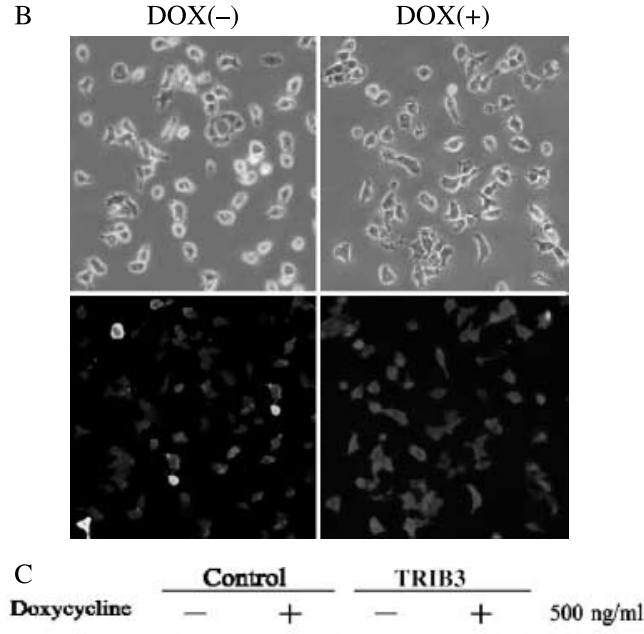

TRIB3

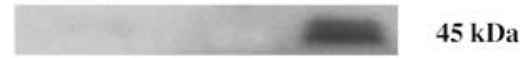

$\alpha$-Tubulin

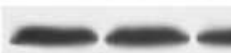

$55 \mathrm{kDa}$

D

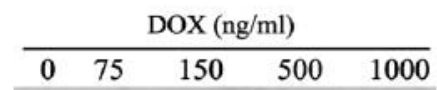

TRIB3

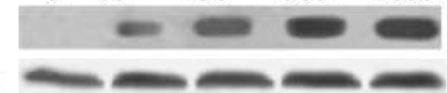

$45 \mathrm{kDa}$

$\alpha$-Tubulin

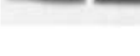

Doxycyclin

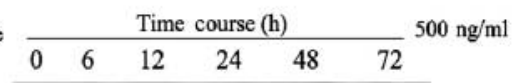

TRIB3

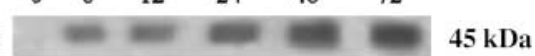

$\alpha$-Tubulin

$55 \mathrm{kDa}$

Figure 2 Characterization of INS1 stable cell line allowing inducible expression of TRIB3. (A) Q-PCR analysis of TRIB3 expression in INS- TRIB3 cells cultured with or without $500 \mathrm{ng} / \mathrm{ml}$ doxycycline for $48 \mathrm{~h}$. (B) Immunofluorescent staining of INS-TRIB3 cells cultured in the presence or absence of $500 \mathrm{ng} / \mathrm{ml}$ doxycycline for $48 \mathrm{~h}$. Phase contrast was shown in the upper panel. (C) Immunoblotting of cell lysates from respectively INS-TRIB3 and parental INS-r $\beta$ cells cultured with or without $500 \mathrm{ng} / \mathrm{ml}$ doxycycline for $48 \mathrm{~h}$. The lower panel showed a blot with anti- $\alpha$-tubulin antibody as an internal loading control. (D) Dose-response (upper panel) and time course of doxycycline induction of TRIB3 proteins in INS-TRIB3 cells. For studying time course, cells were cultured in medium containing $500 \mathrm{ng} / \mathrm{ml}$ doxycycline at the indicated times. For studying dose-response, cells were cultured with the indicated doses of doxycycline (Dox) for $48 \mathrm{~h}$.

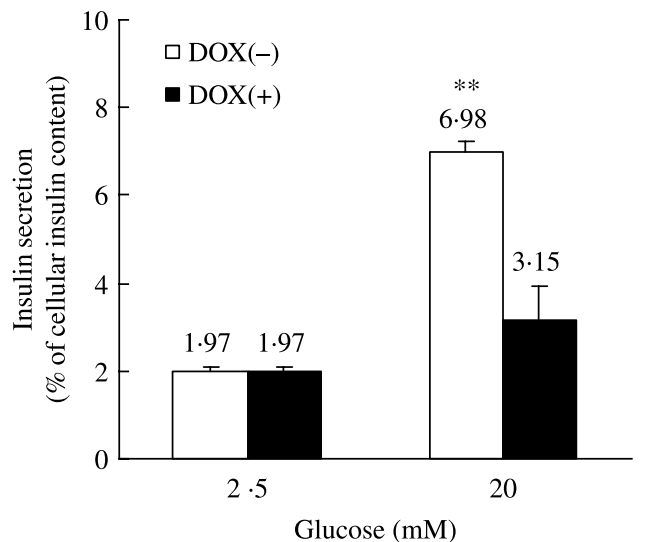

Figure 3 The effect of TRIB3 on glucose-stimulated insulin secretion. TRIB3 cells were cultured with or without $500 \mathrm{ng} / \mathrm{ml}$ doxycycline in the standard medium $(11.2 \mathrm{mM}$ glucose) for $48 \mathrm{~h}$ and then equilibrated in the $2.5 \mathrm{mM}$ glucose medium for a further $5 \mathrm{~h}$. The glucose-stimulated insulin secretion of TRIB3 cell was expressed as a percentage of cellular insulin content. Data represent mean \pm s.D. of three independent experiments $\left({ }^{* *} P<0 \cdot 01\right)$.

Flow cytometric analysis (Beckman Counter Epics XL, Fullerton, CA, USA) was performed with excitation at 488 and emission at $535 \mathrm{~nm}$.

For XOD measurement, $2 \times 10^{5}$ cells seeded in 6-well plates were cultured for $96 \mathrm{~h}$ with or without $500 \mathrm{ng} / \mathrm{ml}$ doxycycline under indicated glucose concentrations. Cytosolic proteins were extracted by centrifugation after 3-cycles of freezing-thaing. XOD concentration was measured using XOD measurement kit (Jiancheng Technology, Nanjing, China).

\section{$R N A$ interference}

Double-stranded RNA duplexes corresponding to rat TRIB3 (5'-ATC TCT GGC TGC TTC TGC CGA TGT T-3'; He et al. 2006) were used for transfection of INS1-derived cells using lipofectamine 2000. The following negative control siRNA was used: 5'-UUC UCC GAA CGU GUC ACG UTT-3' (GenePharma, Shanghai, China).

\section{Statistical analysis}

The results are expressed as mean \pm s.D. and the Mann-Whitney $U$ test was used to evaluate the differences between groups. A value of $P<0.05$ and $P<0.01$ were taken to denote statistical significance.

\section{Results}

TRIB3 expression was increased in diabetic GK rat islets

To investigate the possible involvement of TRIB3 in glucotoxicity-induced $\beta$-cell failure, we first analyzed the TRIB3 expression in islets of GK rats at pre-diabetic and diabetic stages. Real-time PCR results showed that TRIB3 mRNA levels in 
islets isolated from hyperglycemic GK rats was up-regulated by $2 \cdot 8$-fold in comparison with those of normal glycemic GK rats (Fig. 1A). We then studied the possible direct impact of high glucose on TRIB3 expression in INS-1 cells.

Dose-response and time-course of glucose on TRIB3 expression in INS-1 cells

As demonstrated by quantitative RT-PCR, TRIB3 mRNA levels in INS-r $\beta$ cells were elevated in a glucose concentration dependent manner (Fig. 1B). TRIB3 expression at high glucose (30 $\mathrm{mM})$ was increased 8 -fold over the basal (5 $\mathrm{mM}$ glucose) level (Fig. 1B). High glucose treatment of INS-r $\beta$ cells also raised TRIB3 transcript levels in a time-dependent manner (Fig. 1C). Over 6-fold increase of TRIB3 expression was observed after 3-day culture with high glucose (Fig. 1C).
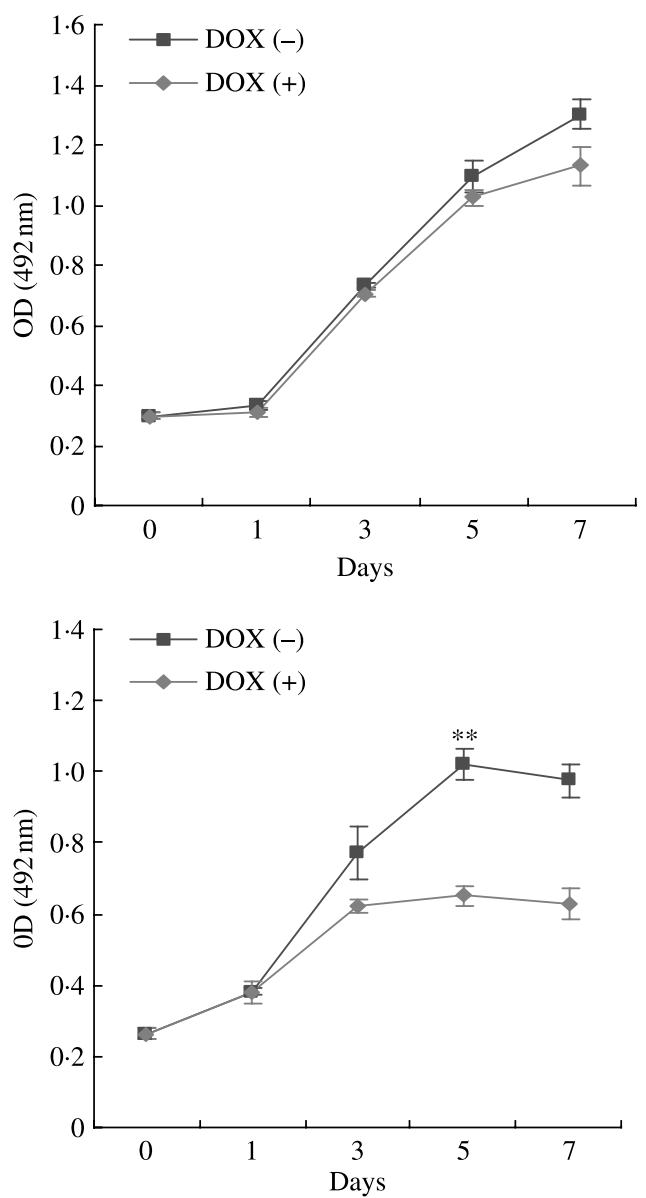

Figure 4 Effects of TRIB3 on INS1 cell growth. Synergistically inhibitory effects of TRIB3 overexpression and chronic high glucose on INS1 cell growth. TRIB3 cells were cultured with medium containing respectively standard $(11.2 \mathrm{mM}$, left panel) or high (30 mM glucose, right panel) glucose, in the presence of absence of $500 \mathrm{ng} / \mathrm{ml}$ doxycycline for $0,1,3,5$, and 7 days. Data represent three separate experiments. $(* * P<0 \cdot 01)$.
Generation and characterization of INS1 stable cell line allowing inducible expression of TRIB3

To further investigate the implication of TRIB3 in glucotoxicity-induced $\beta$-cell dysfunction, we established stable cell lines permitting inducible expression of TRIB3. The INS $\mathrm{r} \beta$ cells were cotransfected with plasmids PUHD10-3 (Gossen et al. 1995), carrying rat TRIB3, and a plasmid pTK-hygro containing the hygromycin-resistance marker. Hygromycinresistant clones were screened by Northern blotting for clones positively expressing TRIB3 after doxycycline induction. The clone, termed, INS-TRIB3, which show high-level induction with the lowest background, was selected for the present study. The cells were induced with indicated concentrations of doxycycline for specified time and the TRIB3 expression were analyzed respectively by real-time PCR (Fig. 2A), immunofluorescent staining (Fig. 2B) and western blotting (Fig. 2C). As shown in Fig. 2A-C, both TRIB3 transcripts and proteins were induced in a doxycycline-dependent manner. Doxycycline alone did not affect endogenous TRIB3 expression in parental INS-r $\beta$ (Fig. 2C). The time course and dose-response of doxycycline-induction in INS-TRIB3 cells are shown in Fig. 2D.

\section{Induction of TRIB3 impaired glucose-stimulated insulin secretion}

Induction of TRIB3 with $500 \mathrm{ng} / \mathrm{ml}$ doxycycline for $48 \mathrm{~h}$ resulted in impaired glucose-stimulated insulin secretion in INSTRIB3 cells (Fig. 3). Therefore, overexpression TRIB3 mimicked the inhibitory effects of chronic high glucose on insulin secretion. These results support the notion that TRIB3 is implicated in $\beta$-cell glucotoxicity.

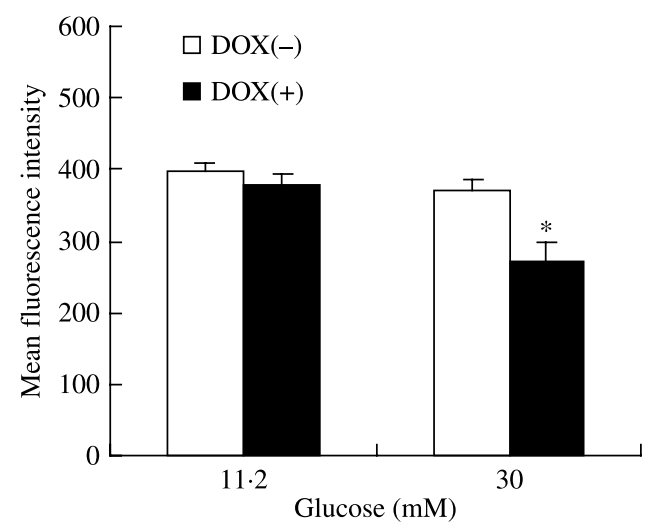

Figure 5 Effects of TRIB3 on INS1 mitochondrial membrane potential. Synergistically inhibitory effects of TRIB3 overexpression and chronic high glucose on INS1 cell $\Delta \Psi \mathrm{m}$. INS-TRIB3 cells were cultured for 4 days in respectively standard or high glucose medium with or without $500 \mathrm{ng} / \mathrm{ml}$ doxycycline. Data represent three separate experiments. $\left({ }^{* *} P<0 \cdot 01\right)$. 
A

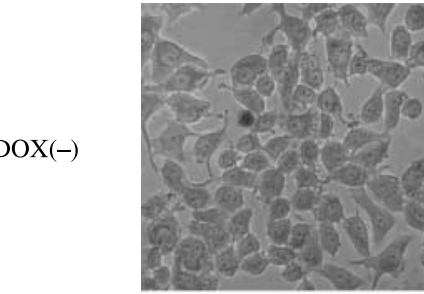

$\operatorname{DOX}(+)$

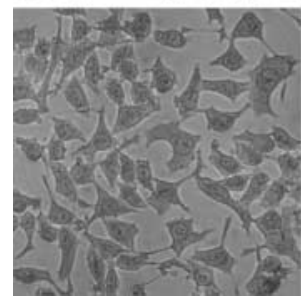

$30 \mathrm{mM}$
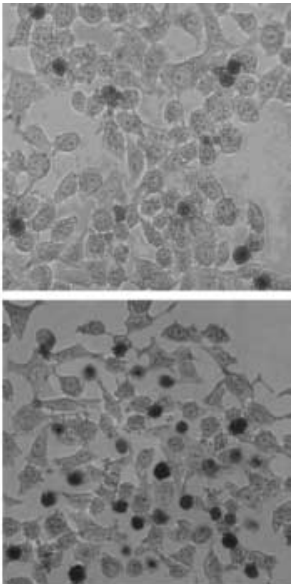

B
Doxycycline

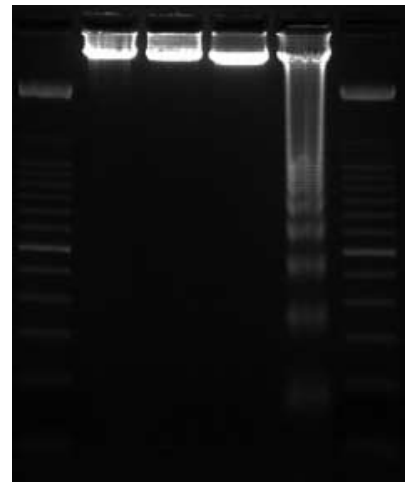

$\mathrm{C}$

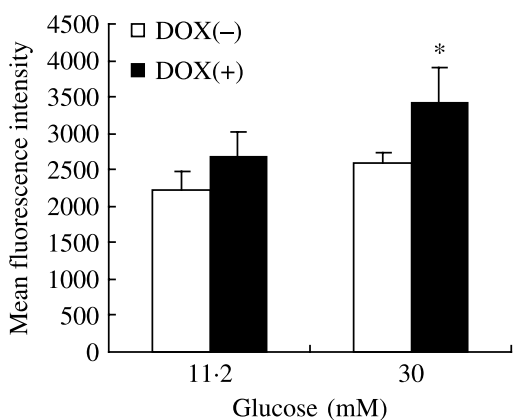

$\mathrm{D}$

$11 \cdot 2 \mathrm{mM}$
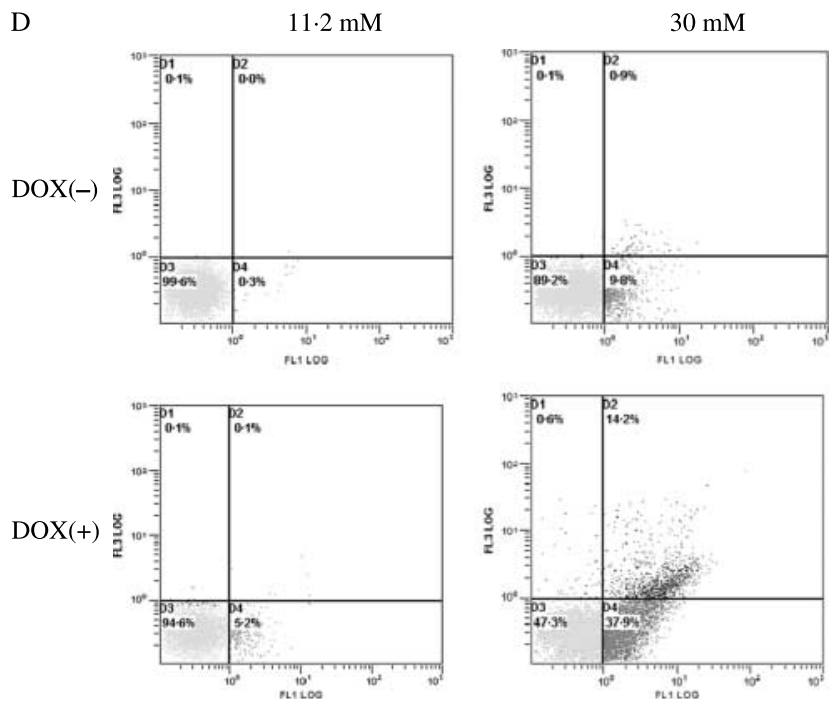

Figure 6 Synergistic effects of TRIB3 overexpression and high glucose on cell apoptosis. (A) Apoptosis in INS-TRIB3 cells using TUNEL staining, (B) DNA fragmentation, (C) caspase-3 activity, and (D) Annexin V-PI double staining. TRIB3 cells were cultured for 4 days in medium containing respectively standard $(11.2 \mathrm{mM})$ and high $(30 \mathrm{mM})$ glucose, in the presence or absence of $500 \mathrm{ng} / \mathrm{ml}$ doxycycline. $\left({ }^{*} P<0 \cdot 05\right)$. 
Effects of TRIB3 on INS1 cell growth

Induction of TRIB3 combined with chronic high glucose caused synergistic right shift of growth retardation in INSTRIB3 cells (Fig. 4).

\section{Effects of TRIB3 on INS1 mitochondrial membrane potential}

The mitochondrial membrane potential $(\Delta \Psi \mathrm{m})$ was measured by flow cytometry using the potential-sensitive probe $\operatorname{DiOC}_{6}(3)$. As shown in Fig. 5, induction of TRIB3 led to $\Delta \Psi \mathrm{m}$ depolarization in INS1 cells cultured under high glucose condition, also suggesting synergistic effects in causing mitochondrial defects. We then further investigated the correlation between TRIB3- and glucotoxicity-evoked- $\beta$-cell dysfunction.

Overexpression of TRIB3 synergistically deteriorated high-glucoseinduced apoptosis

We studied apoptosis in INS-TRIB3 cells using TUNEL staining (Fig. 6A), DNA fragmentation (Fig. 6B), caspase-3 activity (Fig. 6C), and Annexin V-PI double staining (Fig. 6D).
As shown by sensitive TUNEL staining, treatment of INSTRIB3 cells with $30 \mathrm{mM}$ glucose for 4 days caused moderate apoptosis (Fig. 6A, upper panel). Induction of TRIB3 under standard glucose conditions did not cause apoptosis (Fig. 6A, left panel). However, overexpression of TRIB3 synergistically increased chronic glucose-induced apoptosis in INS-TRIB3 cells (Fig. 6A, right panel). This synergistic effect was further confirmed using DNA fragmentation (Fig. 6B), caspase-3 activity (Fig. 6C), Annexin V-PI double staining (Fig. 6D). By contrast, neither TRIB3 overexpression nor high glucose alone could cause such deleterious consequences on INS1 cell apoptosis.

\section{Knockdown of TRIB3 reduced apoptosis}

As demonstrated in Fig. 7A, TRIB3 silencing largely prevented the synergistic effects of TRIB3 and high glucose. These data suggested that TRIB3 overexpression played a predominant role in this synergistic effect and TRIB3 was at least partially responsible for high-glucose-induced apoptosis. The efficiency of siRNA knock down was well demonstrated in Fig. 7B.

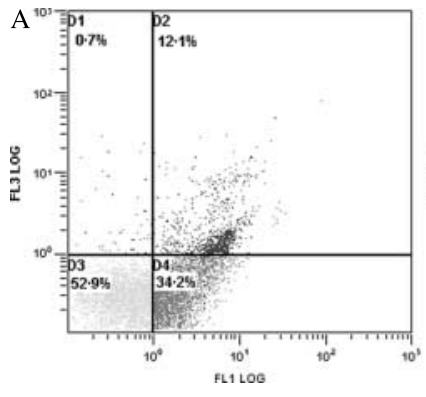

TRIB3

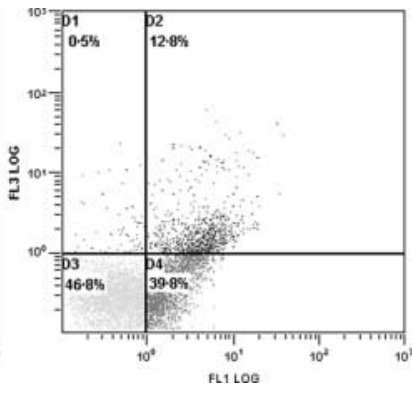

SiRNA control

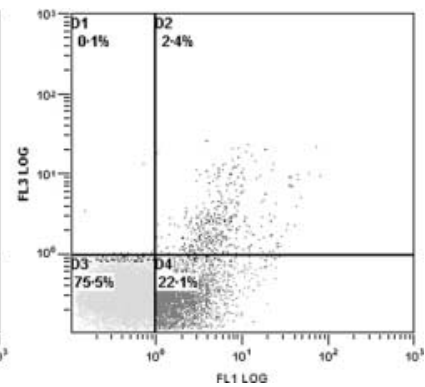

SiRNA TRIB3

B
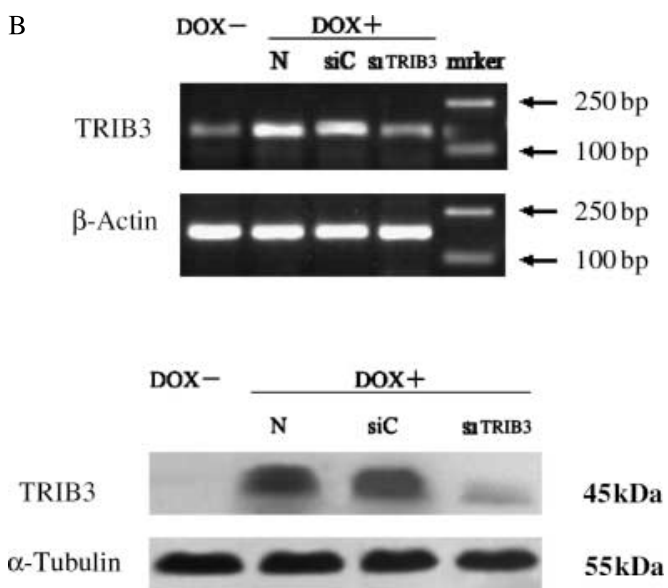

Figure 7 Effects of TRIB3 silencing on the synergy of TRIB3 overexpression and high glucose. (A) After transfection with TRIB3 siRNA for 2 days. INS-TRIB3 cells were cultured for 4 days in medium containing $30 \mathrm{mM}$ glucose plus $500 \mathrm{ng} / \mathrm{ml}$ doxycycline. Apoptosis was assessed by Annexin V-PI double staining. (B) TRIB3 expression was measured in parallel experiments by RT-PCR (upper panel) and western blot (Lower panel). 

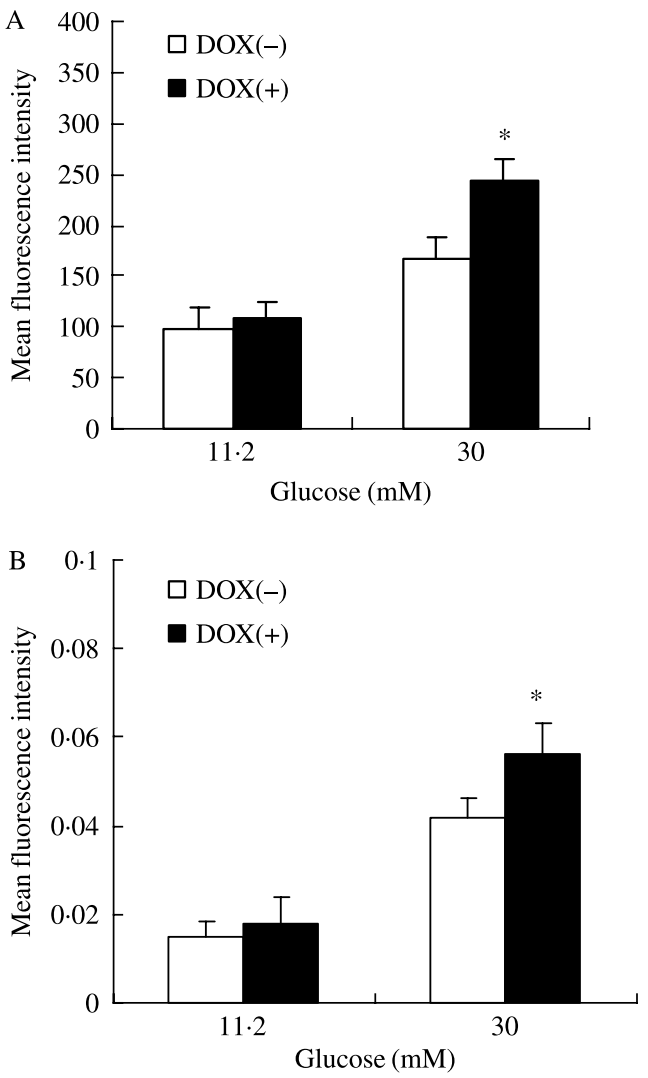

Figure 8 Effects of TRIB3 overexpression on high-glucose-evoked oxidative stress. (A) Induction of TRIB3 facilitated the high-glucoseelicited increase in ROS production and (B) cellular XOD content. INS-TRIB3 cells were cultured for 4 days in medium containing respectively standard $(11.2 \mathrm{mM})$ and high $(30 \mathrm{mM})$ glucose, in the presence or absence of $500 \mathrm{ng} / \mathrm{ml}$ doxycycline. Data represent three independent experiments. $\left({ }^{*} P<0 \cdot 05\right)$.

\section{Overexpression of TRIB3 facilitated high-glucose-induced oxidative stress}

It has been well documented that chronic high glucose causes oxidative stress in islet $\beta$-cells and insulinoma cells (Robertson 2006). We therefore investigated the possible involvement of TRIB3 in high-glucose-induced ROS production. Flow cytometric analysis showed that the induction of TRIB3 enhanced high-glucose-induced ROS production (Fig. 8A). Consistently the high-glucose-elicited cellular XOD concentration was also increased by induction of TRIB3 (Fig. 8B). However, the synergistic effects were not as pronounced as those on cell apoptosis. We therefore studied possible alternative underlying mechanisms.

\section{ER stress induced TRIB3 expression in INS1 cells}

It is well known that chronic high glucose elicits ER stress (Wang et al. 2005, Marchetti et al. 2007, Eizirik et al. 2008). As shown in Fig. 9A, the ER stress inducer, thapsigargin, increased the

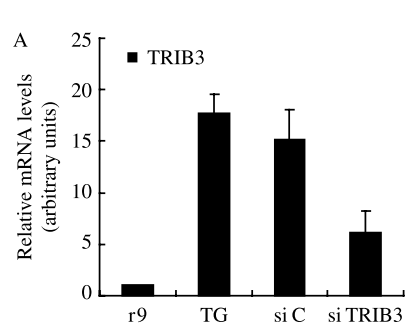

B
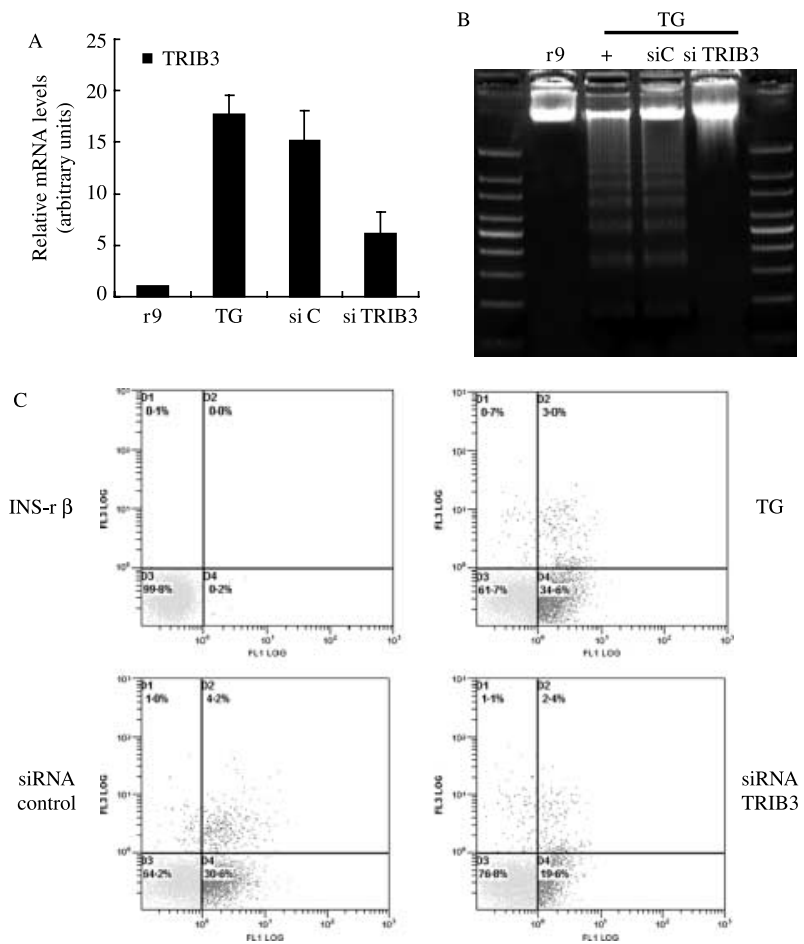

Figure 9 Involvement of TRIB3 in ER-stress-induced apoptosis. (A) Real-time PCR showed that ER stress markedly up-regulated TRIB3 expression, which was diminished by TRIB3 knockdown. (B) ER stressevoked DNA fragmentation was prevented by TRIB3 silencing. (C) Annexin V-PI double staining also demonstrated that TRIB3 siRNA diminished thapsigargin-induced apoptosis. Two days after siRNA transfection, INS-r $\beta$ cells were treated with $1 \mu \mathrm{M}$ thapsigargin for $24 \mathrm{~h}$.

TRIB3 expression by 17 -fold in parental INS-r $\beta$ cells, which was specifically inhibited by TRIB3 silencing.

\section{Knockdown of TRIB3 prevented ER stress-induced apoptosis}

TRIB3 knockdown resulted in marked reduction in thapsigargin-induced apoptosis in INS-r $\beta$ cells, as demonstrated by both DNA fragmentation (Fig. 9B) and Annexin V-PI double staining (Fig. 9C).

\section{Discussion}

Type 2 diabetes is characterized by both insulin resistance and $\beta$-cell dysfunction (Cavaghan et al. 2000). It has been demonstrated that the $\beta$-cell dysfunction is related to chronic hyperglycemia and ER stress (Maedler et al. 2003). However, the underlying mechanisms are not well understood.

During progression of type 2 diabetes, hyperglycemia is an important factor that contributes to advancing $\beta$-cell failure and development of diabetes complications (Federici et al. 2001). Several studies have demonstrated that chronic exposure of $\beta$ cells to high glucose results in $\beta$-cell dysfunction and 
apoptosis (Maedler et al. 2001). The GK rat is a spontaneously diabetic animal model of non-insulin-dependent diabetes mellitus, which is characterized by progressive loss of $\beta$-cell mass and function in the pancreatic islets (Koyama et al. 1998).

TRIB3 was found to possess various cellular biological functions. TRIB3 can inhibit the insulin signaling pathway by binding AKT and associating with the onset of insulin resistant. In addition, TRIB3 regulates ER stress through the ATF4/ CHOP pathway (Ohoka et al. 2005, Carracedo et al. 2006). However, the relationship between TRIB3 and high-glucoseinduced $\beta$-cell apoptosis has not been published.

In the present paper, we demonstrate for the first time that TRIB3, the endogenous inhibitor of AKT and insulin signaling, is expressed in $\beta$ cells. The TRIB3 expression is significantly increased in islets isolated from hyperglycemic GK rats comparing with normal glycemic controls. High-glucoseinduced TRIB3 expression in a time- and dose- dependent manner in INS1 cells. In order to investigate the effect of TRIB3 on $\beta$-cell dysfunction, we established an INS1 stable cell line allowing inducible expression of TRIB3 and confirmed that TRIB3 expression was induced by doxycycline in a dose- and time- dependent manner in the established cell line. In high glucose condition, induction of TRIB3 through genetic manipulation mimicked the glucotoxic effects on insulin secretion and cell growth in INS1 cells. Moreover, the induction of TRIB3 also synergistically enhanced high-glucose-elicited apoptosis in INS1 cells. However, the number of apoptotic cells was significantly reduced following siRNA knockdown of TRIB3 expression, suggesting that TRIB3 participated in highglucose-induced cell apoptosis.

It has been confirmed that high-glucose-generated oxidativestress in INS1 cells (Robertson 2006) and high glucose resulted in ER stress in $\beta$ cells (Wang et al. 2005, Marchetti et al. 2007). We showed here that the classic ER stress-producer, thapsigargin, mimicked the high glucose effects on upregulation of TRIB3 and generation of apoptosis in cultured INS1 cells and these effects were specifically prevented by siRNA knock down of TRIB3, indicating that ER-stress could be one of the major mechanisms underlying glucotoxicity induced $\beta$-cell apoptosis. Insulin and insulin growth factor 1 activate AKT through insulin receptor (IR), IR substrates (IRS-1 and -2), phosphoinositide 3-kinase, and phosphoinositide-dependent-kinase cascade (Dickson \& Rhodes 2004). The essential role of IR signaling in regulation of the growth and survival of pancreatic $\beta$ cells has been well demonstrated in transgenic mice deficient in IRS2, Akt2, and PDK1 (Lee \& White 2004, Elghazi et al. 2007). Therefore, we hypothesize that TRIB3 may induce $\beta$-cell dysfunction and apoptosis through its inhibitory effects on AKT (Du et al. 2003). Furthermore, its suppressive function on insulin sensing in the liver of experimental animals has been well established (Du et al. 2003, Koo et al. 2004, Koh et al. 2006, Matsushima et al. 2006). Consequently, ER stress-induced up-regulation of TRIB3 could be a common mechanism underlying both insulin resistance and $\beta$-cell failure.

In addition, we also found that the release of cytochrome C was increased, the $\Delta \Psi_{\mathrm{m}}$ of mitochondria was decreased, caspase-3 activity was up-regulated and ROS content was increased in TRIB3 overexpressing $\beta$ cells in high glucose condition, suggesting that these factors might be involved in the mechanisms of TRIB3 participating in high-glucose-induced cell apoptosis.

In conclusion, up-regulation of TRIB3, a native inhibitor of insulin-receptor signaling, is implicated in glucotoxicity- and ER-stress-induced $\beta$-cell failure. TRIB3 could be a potential pharmacological target for prevention and treatment of type 2 diabetes.

\section{Declaration of interest}

There is no conflict of interest that could be perceived as prejudicing the impartiality of the research reported.

\section{Funding}

This study was supported by National Basic Research Program of China (No. 2006 CB503906 to LOU), HI-TECH Research and Development Program of China (No. 2006AA02A113 to LOU), National Nature Science Foundation of China (No. 30570889 to LOU) and by the Swiss National Foundation (No. $310000116750 / 1$ to $\mathrm{CBW})$.

\section{References}

Boudeau J, Miranda-Saavedra D, Barton GJ \& Alessi DR 2006 Emerging roles of pseudokinases. Trends in Cell Biology 16 443-445.

Carracedo A, Gironella M, Lorente M, Garcia S, Guzmán M, Velasco G \& Iovanna JL 2006 Cannabinoids induce apoptosis of pancreatic tumor cells via endoplasmic reticulum stress-related genes. Cancer Research 66 6748-6755.

Cavaghan MK, Ehrmann DA \& Polonsky KS 2000 Interactions between insulin resistance and insulin secretion in the development of glucose intolerance. Journal of Clinical Investigation 106 329-333.

Dickson LM \& Rhodes CJ 2004 Pancreatic $\beta$-cell growth and survival in the onset of type 2 diabetes: a role for protein kinase B in the Akt? American Journal of Physiology. Endocrinology and Metabolism 287 E192-E198.

Du K, Herzig S, Kulkarni RN \& Montminy M 2003 TRB3: a tribbles homolog that inhibits Akt/PKB activation by insulin in liver. Science 300 1574-1577.

Eizirik DL, Cardozo AK \& Cnop M 2008 The role of endoplasmic reticulum stress in diabetes mellitus. Endocrine Reviews 29 42-61.

Elghazi L, Rachdi L, Weiss AJ, Cras-Méneuur C \& Bernal-Mizrachi E 2007 Regulation of beta-cell mass and function by Akt/protein kinase B signaling pathway. Diabetes, Obesity and Metabolism 9 147-157.

Federici M, Hribal M, Perego L, Ranalli M, Caradonna Z, Perego C, Usellini L, Nano R, Bonini P, Bertuzzi F et al. 2001 High glucose causes apoptosis in cultured human pancreatic islets of Langerhans: a potential role for regulation of specific $\mathrm{Bcl}$ family genes toward an apoptotic cell death program. Diabetes $\mathbf{5 0}$ 1290-1301.

Gossen M, Freundlieb S, Bender G, Müller G, Hillen W \& Bujard H 1995 Transcriptional activation by tetracyclines in mammalian cells. Science $\mathbf{2 6 8}$ 1766-1769.

Grill V \& Björklund A 2001 Overstimulation and beta-cell function. Diabetes 50 S122-S124.

Harding HP, Zeng H, Zhang Y, Jungries R, Chung P, Plesken H, Sabatini DD \& Ron D 2001 Diabetes mellitus and exocrine pancreatic dysfunction in perk $-/-$ mice reveals a role for translational control in secretory cell survival. Molecular Cell 7 1153-1163.

He L, Simmen FA, Mehendale HM, Ronis MJ \& Badger TM 2006 Chronic ethanol intake impairs insulin signaling in rats by disrupting Akt association with the cell membrane. Role of TRB3 in inhibition of Akt/protein kinase B activation. Journal of Biological Chemistry 281 11126-11134.

Journal of Endocrinology (2008) 199, 407-416 
Koh HJ, Arnolds DE, Fujii N, Tran TT, Rogers MJ, Jessen N, Li Y, Liew CW, Ho RC, Hirshman MF et al. 2006 Skeletal muscle- selective knockout of LKB1 increases insulin sensitivity, improves glucose homeostasis, and decreases TRB3. Molecular and Cellular Biology 26 8217-8227.

Koo SH, Satoh H, Herzig S, Lee CH, Hedrick S, Kulkarni R, Evans RM, Olefsky J \& Montminy M 2004 PGC-1 promotes insulin resistance in liver through PPAR- $\alpha$-dependent induction of TRB-3. Nature Medicine 10 530-534.

Koyama M, Wada R, Sakuraba H, Mizukami H \& Yagihashi S 1998 Accelerated loss of islet beta cells in sucrose-fed Goto-Kakizaki rats, a genetic model of noninsulin-dependent diabetes mellitus. American Journal of Pathology 153 537-545.

Laybutt DR, Preston AM, Akerfeldt MC, Kench JG, Busch AK, Biankin AV \& Biden TJ 2007 Endoplasmic reticulum stress contributes to $\beta$-cell apoptosis in type 2 diabetes. Diabetologia 50 752-763.

Lee YH \& White MF 2004 Insulin receptor substrate proteins and diabetes. Archives of Pharmacological Research 207 361-370.

Maedler K, Spinas GA, Lehmann R, Sergeev P, Weber M, Fontana A, Kaiser N \& Donath MY 2001 Glucose induces beta-cell apoptosis via upregulation of the Fas receptor in human islets. Diabetes 50 1683-1690.

Maedler K, Oberholzer J, Bucher P, Spinas GA \& Donath MY 2003 Monounsaturated fatty acids prevent the deleterious effects of palmitate and high glucose on human pancreatic beta-cell turnover and function. Diabetes 52 726-733.

Marchetti P, Bugliani M, Lupi R, Marselli L, Masini M, Boggi U, Filipponi F, Weir GC, Eizirik DL \& Cnop M 2007 The endoplasmic reticulum in pancreatic beta-cells of type 2 diabetes patients. Diabetologia 50 2486-2494.

Matsushima R, Harada N, Webster NJ, Tsutsumi YM \& Nakaya Y 2006 Effect of TRB3 on insulin and nutrient-stimulated hepatic p70 S6 kinase activity. Journal of Biological Chemistry 281 29719-29729.

Mayumi-Matsuda K, Kojima S, Suzuki H \& Sakata T 1999 Identification of a novel kinase-like gene induced during neuronal cell death. Biochemical and Biophysical Research Communications 258 260-264.
Muoio DM \& Newgard CB 2008 Molecular and metabolic mechanisms of insulin resistance and $\beta$-cell failure in type 2 diabetes. Nature Reviews. Molecular Cell Biology 9 193-205.

Ohoka N, Yoshii S, Hattori T, Onozaki K \& Hayashi H 2005 TRB3, a novel ER stress-inducible gene, is induced via ATF4-CHOP pathway and is involved in cell death. EMBO Journal 24 1243-1255.

Robertson RP 2006 Oxidative stress and impaired secretion in type 2 diabets. Current Opinion in Pharmacology 6 1-5.

Shapiro AM, Hao E, Rajotte RV \& Kneteman NM 1996 High yield of rodent islets with intraductal collagenase and stationary digestion: a comparison with standard technique. Cell Transplantation 5 631-638.

Shih CM, Ko WC \& Wu JS 2004 Mediating of caspase-independent apoptosis by cadmium through the mitochondria-ROS pathway in MRC-5 fibroblasts. Journal of Cellular Biochemistry 91 384-397.

Wang H \& Iynedjian PB 1997 Modulation of glucose responsiveness of insulinoma beta-cells by graded overexpression of glucokinase. PNAS 94 4372-4377.

Wang H, Gauthier BR, Hagenfeldt-Johansson KA, Iezzi M \& Wollheim CB 2002 Foxa2 (HNF3 3 ) controls multiple genes implicated in metabolismsecretion coupling of glucose-induced insulin release. Journal of Biological Chemistry 277 17564-17570.

Wang H, Kouri G \& Wollheim CB 2005 ER stress and SREBP-1 activation are implicated in $\beta$-cell glucolipotoxicity. Journal of Cell Science 118 3905-3915.

Received in final form 31 August 2008

Accepted 22 September 2008

Made available online as an Accepted Preprint 25 September 2008 